\title{
Cartelas de cores: uma proposta metodológica
}

João Dalla Rosa Júnior

Doutor, SENAI CETIQT / joaodrir@yahoo.com.br

Orcid: 0000-0003-3896-5417 / lattes 


\title{
Cartelas de cores: uma proposta metodológica
}

\begin{abstract}
RESUMO
O presente artigo tem por objetivo propor uma metodologia de criação de cartelas de cores a partir da identificação das etapas de projeto. A proposta consiste em estabelecer a cartela como uma síntese da relação de variáveis que direcionam a seleção de cores por meio de critérios objetivos. A metodologia se apoia no diagrama do funil de decisões apresentado por Baxter e demarca 3 etapas específicas: marca, tendências e tema-moodboard. As etapas são contextualizadas nas fases de pesquisa e geração de ideias e detalhadas de acordo com a prática de criação de cartelas de cores para o desenvolvimento de produtos.
\end{abstract}

Palavras-chave: Design de moda. Cartelas de cores. Metodologia projetual. 


\title{
Color ranges: a methodological approach
}

\begin{abstract}
This paper propose a methodology for creating color ranges from the identification of the design steps. The proposal consists of establishing the color range as a synthesis of the relation of variables that guide the selection of colors by objective criteria. The methodology relies on the Baxter decision funnel diagram and outlines 3 specific steps: branding, trends and theme-moodboarding. The steps are contextualized in the phases of research and generation of ideas and detailed according to the practice of creating color charts for the development of products
\end{abstract}

Keywords: Fashion design. Color ranges. design methodology. 


\title{
Gráficos de colores: una propuesta metodológica
}

\begin{abstract}
RESUMEN
Este artículo tiene como objetivo proponer una metodología para crear tablas de colores a partir de la identificación de las etapas de diseño. La propuesta consiste en establecer el cuadro como una síntesis de la lista de variables que guían la selección de colores a través de criterios objetivos. La metodología se basa en el diagrama de embudo de decisión presentado por Baxter y describe 3 pasos específicos: marca, tendencias y tema-estado de ánimo. Los pasos se contextualizan en las fases de investigación y generación de ideas y se detallan de acuerdo con la práctica de crear tablas de colores para el desarrollo de productos.
\end{abstract}

Palabras clave: Diseño de moda. cartas de colores. metodología de diseño. 


\section{Introdução}

As cartelas de cores correspondem a um material decisivo na prática de desenvolvimento de produtos que caracteriza o trabalho profissional dos designers de moda. Neste sentido, as cartelas se configuram como um resultado de diferentes fatores que são associados no decorrer do projeto de coleção de moda. Embora muitos designers atuem de modo intuitivo para a elaboração das cartelas de cores, uma vez que elas se relacionam às ações criativas que a prática do design proporciona, não podemos deixar de evidenciar que esta intuição é acompanhada de estratégias que, mesmo não conscientes, permitem a efetividade das cores na aplicação dos produtos.

Sobre as cartelas de cores, encontramos poucas publicações que as utilizem como objeto de pesquisa científica. Por serem consideradas um tipo de informação valiosa para o círculo das tendências de moda, as cores são compreendidas como um elemento fundamental em publicações de grandes bureaux e, por esta razão, são mais analisadas pelo estímulo que representam na prática de desenvolvimento de produto, do que como objeto de estudo para a compreensão científica do modo pelo qual são escolhidas.

Entre as principais publicações dos bureaux, temos o Carlin e Promostyl, responsáveis por promoverem a divulgação das tendências de moda a partir da projeção das estações futuras. Alguns cadernos de tendências, promovidos por instituições como SENAC, SENAI E SEBRAE, cumprem a mesma função no âmbito nacional em comparação aos cadernos internacionais, cujos custos são mais altos e seu acesso mais difícil. Estas publicações favorecem a percepção de seleções de cores e harmonias que permitem uma 
apreciação estética sobre as qualidades das referências cromáticas, tendo em vista sua aplicação no desenvolvimento dos produtos. No entanto, estas publicações não proporcionam nenhuma orientação sobre uma metodologia de aplicação das cores no âmbito do projeto de moda especificamente.

Em relação às publicações acadêmicas, destacamos as orientações fornecidas por Doris Treptow (2013) e Frings (2012), que embora sejam genéricas em relação ao número de cores que uma cartela pode ter, fornecem um direcionamento no contexto geral de descrição das etapas de desenvolvimento de produto em design de moda. O livro de Clarice Garcia (2018), nesse sentido, se torna mais específico em relação ao tema das cores, no entanto, seu enfoque recai sobre as tendências e as considerações em relação à função de escolha das cores e a formação das cartelas não parecem apresentar alguma especificidade.

Partindo deste contexto, o presente artigo tem por objetivo propor uma metodologia de criação de cartelas de cores a partir da identificação das etapas de projeto. A proposta consiste em estabelecer a cartela como uma síntese da relação de variáveis que direcionam a seleção de cores por meio de critérios objetivos. Os critérios visam contemplar as especificidades de projeto no âmbito do mercado industrial de moda e, assim, se vinculam aos parâmetros de identidade das marcas, das tendências e de criação dos designers.

A proposta metodológica para a elaboração das cartelas de cores se apoia no diagrama do funil de decisões apresentado por Baxter (2011, p. 28), já que se insere em uma perspectiva estratégica do desenvolvimento de produto, destacando as decisões orientadas por critérios objetivos. Com isso, ela se coloca diretamente vinculada à compreensão do design thinkng (AMBROSE, 2011), uma vez que dá ênfase à 
dimensão processual do design, salientando o raciocínio que configura o pensamento decorrente da prática projetual (SANCHES, 2017, p. 88).

Para articular o conteúdo da proposta, o artigo está dividido em diferentes seções. Na seção a seguir, os conceitos sobre cor são abordados conjuntamente com as definições sobre o "funil de decisões" aplicados à metodologia de criação de cartelas de cores. Nas demais, são apresentadas as etapas de projeto, tomadas aqui como as variáveis que, de acordo a representação do funil, orientam as decisões para a elaboração da cartela de cor, tornando-a uma síntese do pensamento estratégico. Entre as etapas, destacamos aquelas referentes à pesquisa e à geração de ideias, que buscam mapear as informações sobre a identidade da marca, as tendências de moda e o tema de criação, conforme aponta Treptow (2013, p. 71-85).

\section{Conceitos e definições}

Antes de entrarmos nas questões específicas do método a ser proposto, precisamos explicitar alguns conceitos fundamentais sobre as propriedades das cores, que são os fundamentos pelos quais a metodologia se fundamenta.

A cor, como fenômeno, pode ser definido como resultado de um processo de percepção que ocorre através do olho devido aos estímulos fornecidos pela luz, que é refletida pelos objetos (PEDROSA, 2009). A luz e os objetos, por meio dos pigmentos, influenciam na percepção e, dessa forma, se estabelecem como sistemas que geram a cor. Em relação à sua constituição físico-química, a cor pode ser definida por três categorias: tonalidade, luminosidade e saturação. Embora, os nomes possam variar de acordo com as referências e suas origens linguísticas, como é o caso do 
termo "valor" para luminosidade (ALBERS, 2009, p. 98-99), as três palavras são adotadas aqui porque elas representam mais claramente as definições que são encontradas nas publicações mais difundidas no Brasil (FRASER, 2011; ALBERS, 2009; PEDROSA, 2003).

A tonalidade se refere à referência espectral da cor, isto é, a onda luminosa, e designa as cores propriamente ditas, como verde, vermelho, amarelo, azul, entre outras. A luminosidade congrega a variação de claro e escuro que uma tonalidade possui, isto é, sua variação para o branco e o preto. Como exemplos, podemos citar o rosa, que identifica um vermelho claro, e o azul-marinho, que, na verdade, alude a um azul escuro. Por fim, a saturação se destina a classificar a intensidade de cor de uma referência, ou seja, o quanto a cor vibra em relação a um cinza de mesma luminosidade. Quanto mais intensa uma cor, mas distante do cinza e, portanto, mais saturada ela é. Para exemplificar, podemos pensar na relação entre um amarelo e o bege. O amarelo possui uma saturação alta que o bege não o tem, já que ele é mais cinzento.

As definições acima são importantes porque elas permitem com que mantenhamos um vocabulário comum que coloca a cor sobre categorias pelas quais podemos classificar suas manifestações. Contudo, é necessário evidenciar que estas categorias não representam que a cor seja um elemento que se pode isolar, pois, como demonstra Albers (2009), ela está em constante interação com seu contexto de percepção e facilmente sofre interferências que a fazem parecer assumir outras qualidades de tonalidade, luminosidade e saturação.

Em relação à metodologia proposta neste artigo, ela se apropria do esquema do "funil de decisões" apresentado por Baxter (2011, p. 28). O esquema do funil se fundamenta como "um processo de decisões" aplicado ao desenvolvimento de novos produtos. Ou seja, se destina a avaliar a estratégia 
de negócios e as oportunidades que um novo produto demanda, estabelecendo um procedimento sistemático de etapas a serem percorridas de modo a verificar o risco e as incertezas envolvidas no projeto. O funil permite que seja visualizado o percurso, demonstrando a especificidade que as etapas conferem ao projeto, diminuindo os riscos para sua viabilidade.

No caso da metodologia para as cartelas de cores, o funil é tomado pela sua qualidade prática de representar um caminho que parte de fatores mais amplos para, então, chegar àqueles mais específicos. O objetivo aqui é que a cartela de cores seja entendida como o resultado da aplicação do funil. Ou seja, como objeto que se forma pela realização de etapas específicas que estão associadas ao desenvolvimento de produtos. Com as cartelas de cores, não se pretende enfatizar a dimensão de inovação que está contida na designação de um novo produto, conforme Baxter (2011, p. 29-31) afirma. O enfoque da proposta se destina a compreender que a moda está constantemente gerando produtos e que a lógica do novo é inerente à moda (LIPOVETSKY, 2005; SVEDSEN, 2010). 
Figura 1. Proposta metodológica para cartela de cores.

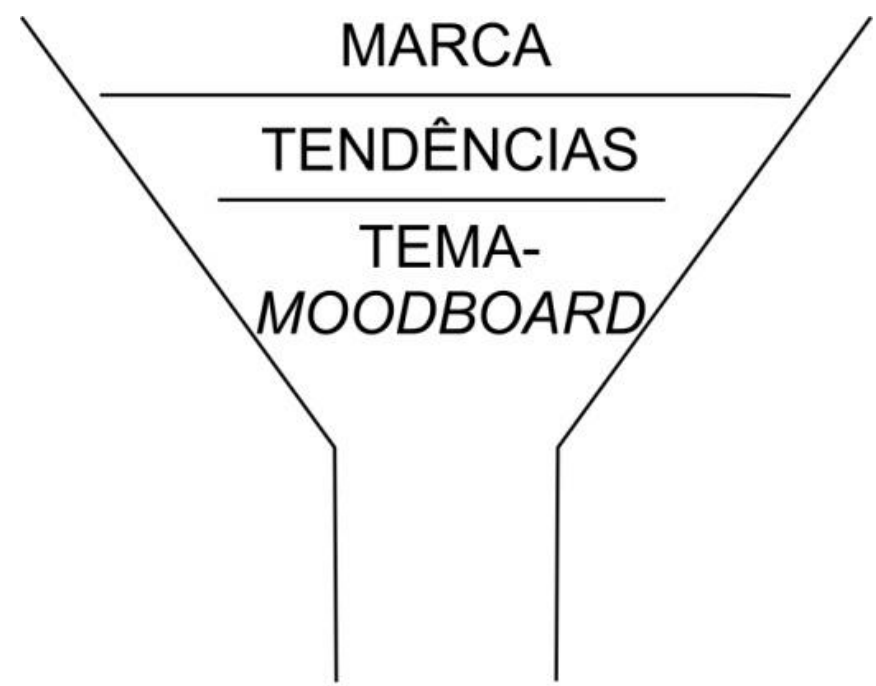

CARTELA DE CORES

Fonte: autor (2019).

Em comparação às etapas sinalizadas por Baxter, o funil proposto para as cartelas de cores é mais enxuto, já que demarca 3 etapas: marca, tendências e tema-moodboard. As três etapas configuram uma metodologia porque estão inseridas nas fases de pesquisa e geração de ideias (AMBROSE, 2011), o que, para as definições de Sanches (2017, p. 103), são "procedimentos para contextualizar e sintetizar parâmetros projetuais" e "procedimentos para gerar e experimentar possibilidades de conexão", respectivamente.

Em nossa compreensão, as etapas "marca" e "tendências" aludem à fase de pesquisa porque buscam coletar informações que serão sintetizadas na cartela de cores. Já, a etapa "tema-moodboard" se direciona à geração de ideias porque envolve um trabalho de criação e que decorre das anteriores. As três culminam na cartela de cores, pois ela se torna a síntese da passagem entre a pesquisa e a geração de ideias. Assim, a adoção do funil de decisões faz com que haja a convergência de informações para que elas sejam aplicadas 
na geração de um objeto, a cartela, que será a diretriz para o desenvolvimento dos produtos. A seguir, passamos às etapas.

\section{Marca}

O primeiro item a ser considerado no funil de decisões relativos à cartela de cores é a marca. A marca corresponde a uma identidade que possui características próprias e que se reflete nos produtos por ela oferecidos ao mercado.

Nesse sentido, o problema de design que caracteriza o trabalho destas marcas se encontra no próprio projeto de moda, isto é, nas coleções que são projetadas sazonalmente. Coordenar a construção dos produtos e o modo como eles se relacionam para a produção de sentido de uma coleção são problemas específicos da prática do design de moda, já que nas demais áreas de desenvolvimento de produto, normalmente as peças são pensadas isoladamente e fora do contexto temporal de produção com que a moda opera. Em outras palavras, a exigência de um novo produto de acordo com a temporalidade da moda, que é, no mínimo, a cada estação, faz com que um dos problemas do projeto de coleção seja a própria continuidade do desenvolvimento dos produtos para a indústria de vestuário, ou seja, a produção do novo.

A continuidade é oferecida pela manutenção de padrões que a marca estabelece. Os padrões se relacionam à identidade da marca, já que se tornam características que o público passa a reconhecer e se identificar, formulando, assim, a noção de life style que a empresa vende.

A cor é um dos elementos que permite a identidade da marca e também aquele que se revela como característica a ser padronizada na aplicação dos produtos. Embora possamos pensar que a cada coleção, novas cores imponham uma mudança, é necessário destacar que, quanto mais 
consolidada a marca, mais os padrões estão estabelecidos e gradativas são as adaptações frentes às novidades demandas pela indústria da moda. Assim, um dos principais critérios a ser empregado na metodologia de criação de cartelas de cores é identificar e especificar os padrões de cores que a empresa utiliza para aplicação nas coleções da marca, de modo a destacar o que é mais recorrente na configuração dos produtos.

A identificação e especificação deve se pautar pela percepção das propriedades de cores mais recorrentes nas coleções da marca. Por propriedades, entendemos as tonalidades que caracterizam a identidade da marca e de seus produtos e de que forma os índices de luminosidade e saturação variam.

Para que a identificação seja mais específica, um caminho de análise é que sejam empregados os contrastes e as harmonias de Itten (2004). Apesar de suas considerações estarem prescritas no contexto do início do século $X X$ e, portanto, apresentar uma compreensão moderna da cor (BARROS, 2007, p. 59-68), os contrastes e as harmonias indicados permitem categorias bastante objetivas para classificar o modo como as marcas empregam as cores nos produtos. Em especial, podemos citar os contrastes de tonalidade, quente-frio, claro-escuro, saturação e complementar, além da harmonia análoga, em tríade, em quadrado e em retângulo.

Para exemplificar, citarei um exemplo. Ele se refere à marca Fábula. Destinada ao segmento infantil, podemos observar através de diferentes coleções que o emprego do contraste de tonalidades e de claro-escuro é recorrente na marca. Através das estampas, fica evidente o emprego de tonalidades saturadas que geram contraste entre si e que são colocadas sobre um fundo escuro, o que produz o contrate de 
claro-escuro. Este procedimento se repete nos produtos de diferentes coleções e, assim, é possível afirmar que esta combinação de cores é um padrão de identidade da marca. Pela identificação e especificação do padrão, ambos contrastes se tornam informações que serão decisivas para a criação da cartela de cores de uma coleção futura, já que para manutenção da identidade da marca e dos produtos, uma cor escura precisará ser selecionada a fim de que possa exercer a função do preto, bem como será necessário contemplar diferentes tonalidades na escolha das cores para que se possa produzir a percepção da diversidade resultante do contraste de tonalidade. Este procedimento não precisará ser adotado, caso a marca opte por criar novas combinações para todos os seus produtos, rompendo com o estilo que a mantém e a identifica, o que representa uma ruptura frente às continuidades que o desenvolvimento de produto e os ciclos da moda apresentam.

Figura 2. Produtos das coleções Holyboly, Aldeia e Bicho Grilo, respectivamente (FABULA, 2018).
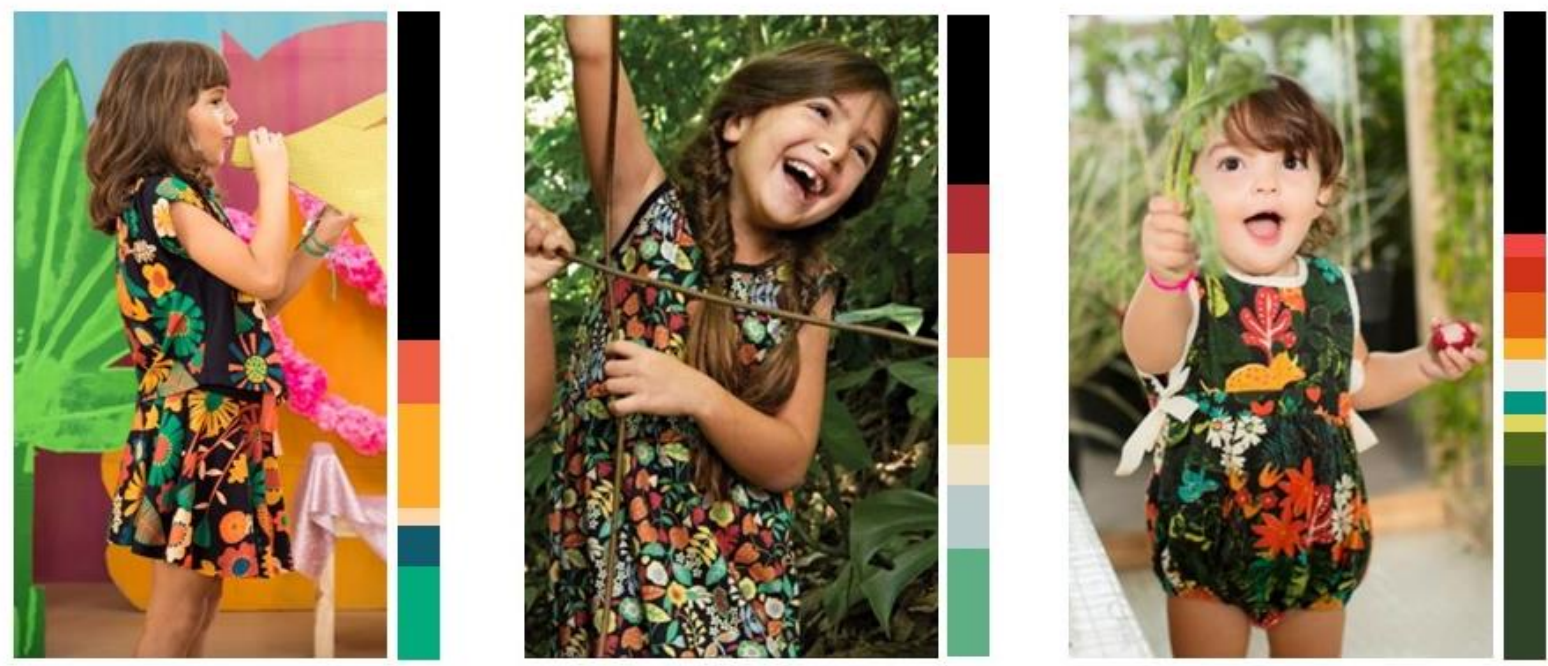

Fonte: Fabula (2018). 
Assim, a primeira grande etapa que se sinaliza na metodologia de criação das cartelas de cores se refere à demarcação dos princípios de combinações de cores que a marca possuí e que caracterizam sua identidade. Marcas jovens podem ter dificuldades em determinar os padrões, mas, ao passo que confirmarem a aceitação do público, poderão adotar critérios mais definidos e, assim, compartilhar das certezas que marcas mais consolidadas possuem e que se tornam categorias objetivas para o desenvolvimento de produto.

\section{Tendências}

As tendências indicam o segundo momento do funil de decisões pelo qual se propõe a metodologia de criação de cartelas de cores. A etapa se destina à pesquisa das tendências e às escolhas de suas referências sobre cores de modo que possam ser adotados e confrontados aos critérios definidos pela etapa da marca.

Como tendências, compreendemos todas as informações que são divulgadas sazonalmente e que tentam indicar direções para o desenvolvimento de produtos. Feiras, semanas de modas, cadernos e portais na internet correspondem aos espaços por onde estas informações circulam e onde elas são vendidas, já que movimentam as expectativas dos profissionais do setor. Cabe destacar que, conforme aponta Michetti (2015), os eventos destinados às tendências impõem o debate sobre a globalização no mundo da moda, visto que as tendências compreendem um mercado internacional que articula as diferenças culturais locais a partir da lógica de domínio e legitimação dos centros da moda, como é o caso de algumas cidades nos Estados Unidos e das principais capitais européias. 
Sobre as informações de cores das tendências, é importante destacar que elas costumam fornecer cartelas, indicando diferentes tonalidades que estarão disponíveis para a produção. Como é descrito por Michetti (2015), as grandes feiras do setor, como é o caso da Première Vision e a Texworld, são formadas por indústrias da cadeia têxtil e que, também, abrangem os fornecedores de pigmentos para a coloração dos tecidos. Assim, as referências de cores divulgadas como tendências representam apostas dos setores produtivos e, mais do que permitir uma liberdade de escolha ao varejo, sentenciam o mercado com aquilo que eles querem que seja comercializado.

Nesse sentido, vale a pena comentar que, embora o mercado de tendências de moda divulgue constantemente novidades sobre cores e outros produtos, os ciclos de cores tendem a ser mais lentos, como indicam diferentes pesquisas (KING, 2017; STANSFIELD; WHITFIELD, 2005). Elas demonstram que há mais continuidades das cores na sequência de estações do que rupturas e que as continuidades são promovidas devido aos investimentos que as indústrias realizam para o fornecimento de matéria-prima para a produção de têxteis e suas colorações. Ou seja, as constantes mudanças sinalizadas não indicam reais mudanças nas cores, mas, sim, na forma de combiná-las, gerando novidades a partir de um rearranjo dos elementos de design, o que caracteriza o conceito de diferenciação promulgado por Adrian Forty (2007).

Além das cores que as tendências indicam, é importante observar como as cores são combinadas, isto é, quais são as harmonias propostas. As harmonias se referem à forma da combinação, já que expressam quantidades de cores e alguns preceitos referentes aos contrates mencionados anteriormente. Elas são encontradas em quase todo tipo de 
publicação, pois favorecem o agrupamento de cores de acordo com alguns conceitos que promovem uma abordagem mais próxima ao estilo e ao comportamento do consumidor, enfatizando a dimensão simbólica do consumo.

Figura 3. Apresentação do portal Pantone para as cores do ano de 2019 e, à direta, indicação das harmonias cromáticas.

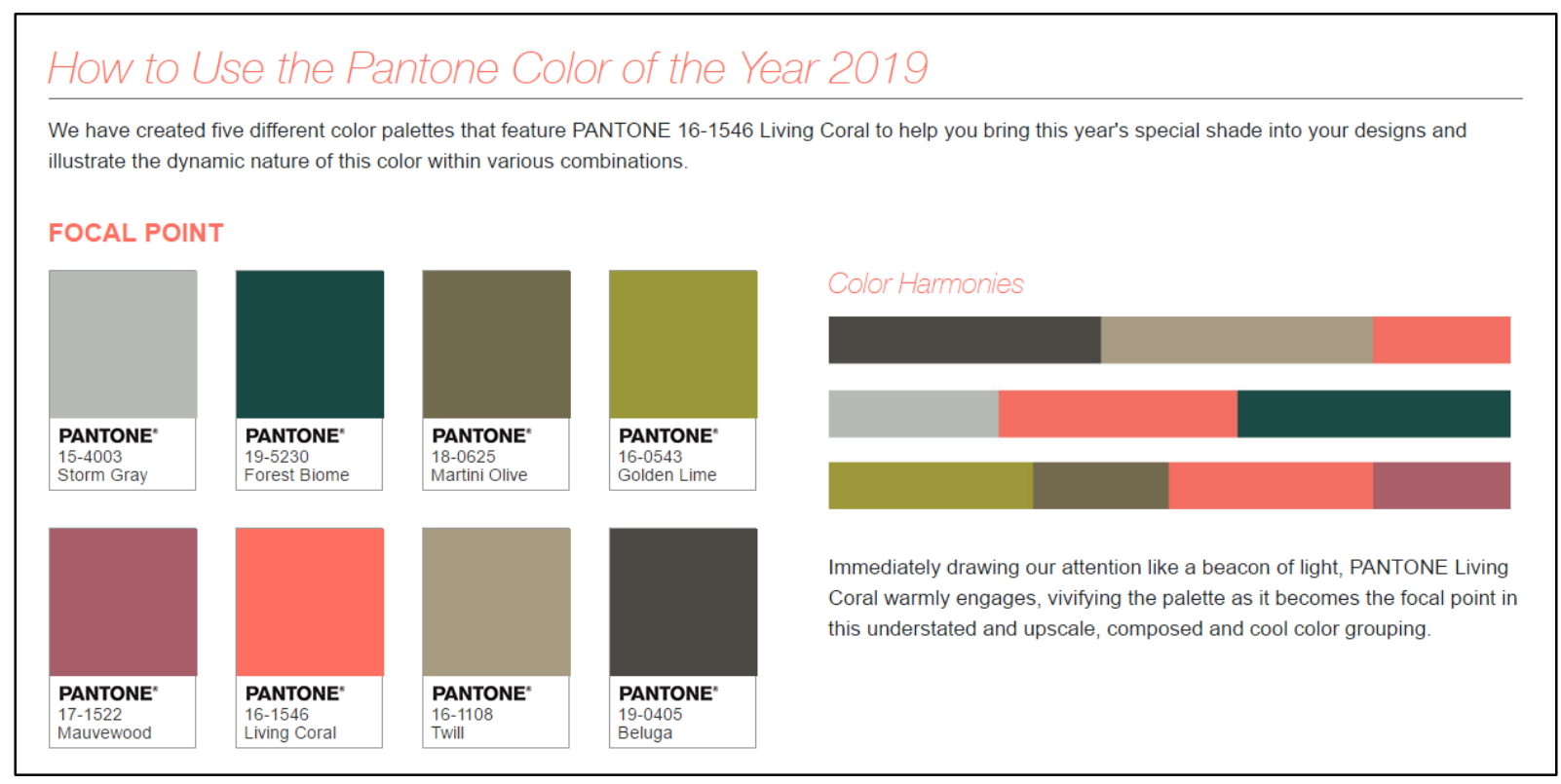

Fonte: Pantone (2019).

As harmonias podem ser encontradas em publicações dos grandes bureaux como WGSN, Promostyl, Carlin, Use Fashion, entre outros. No entanto, não podemos deixar de considerar a especial importância que a empresa Pantone desempenha neste setor, já que é especializada em catálogos de cores para design e apresenta grande adesão no mercado de moda. Como as anteriores, ela apresenta harmonias e suas indicações são tomadas como premissas bastante úteis para aplicação nos produtos. Ademais, é necessário mencionar que o código Pantone é amplamente usado na identificação das cores de tecidos por diferentes fornecedores de matéria-prima no mercado de moda. Assim, é possível afirmar que ao 
considerar as tendências de cores, a fase de pesquisa também compreende o trabalho de contato com os fornecedores e a maneira como eles estão materializando as referências que as tendências apontam.

Frente a isto, a segunda etapa da metodologia prevê que as cores citadas pelas tendências, juntamente como as harmonias, sejam balizadas a partir dos padrões característicos da marca. Tendo em vista que a marca possui critérios já estabelecidos sobre a forma de utilização da cor em relação à sua identidade e a de seus produtos, a pesquisa de tendência proporciona uma observação sobre o que o mercado oferece, no entanto, com um foco bastante objetivo sobre aquelas informações que são coerentes e adequadas aos critérios da marca.

Uma contribuição das pesquisas de tendências e das indicações das harmonias cromáticas é que elas permitem com que as novidades sejam incorporadas aos padrões da marca, de modo a gerar diferenciação de produtos, sem que haja um risco elevado à identidade e ao reconhecimento do estilo da marca pelo seu público. Dessa forma, a criação da cartela de cores passaria pela análise das tendências a partir de critérios objetivos demarcados pelo perfil da marca, o que torna o trabalho do designer mais assertivo em relação à diversidade do mercado de moda.

\section{Tema-moodboard}

O tema se refere à última etapa do funil de decisões. Ele surge como uma referência criativa que é elaborada para o desenvolvimento dos produtos, concentrando, assim, o resultado dos critérios anteriores.

O tema, no projeto em design de moda, corresponde à dimensão conceitual que é estabelecida para que se possa 
desenvolver o projeto de produtos. No campo da moda, há mitos de temas que aludem a lugares, objetos, culturas, livros, entre outros. A origem destes mitos pode ser encontrada nas descrições propostas por Caroline Evans (2002) sobre as origens dos desfiles, quando designers nomeavam suas coleções e também os próprios looks, apresentando, com isso, uma esfera poética para as roupas.

No entanto, é necessário destacar que qualquer referência pode ser tomada como tema de uma coleção, já que ele se estabelece por uma abordagem criativa e visa a atribuição de elementos estéticos para o desenvolvimento de produto. Não é por acaso que Doris Treptow (2013, p. 83-85) menciona a pesquisa temática como uma das etapas projetuais, já que se associa às ações de escolher, selecionar e aprimorar conteúdos de criação, exigindo, portanto, um trabalho de maturação.

O tema, nas etapas metodológicas das cartelas de cores, implica em uma tomada de decisão que concentra ainda as informações para o trabalho do designer: o tema surge como uma resposta que baliza as considerações do perfil da marca e das tendências. Assim, podemos considerar que o tema já sinaliza uma passagem da fase de pesquisa para a geração de ideias, pois demanda uma ação de escolha para o projeto, transformando dados em informação visual.

A passagem é conduzida pelo moodboard, também chamado de painel iconográfico ou semântico, que assume a função de representar o tema através de imagens. Elas, por sua vez, retratam os elementos visuais que nortearão o desenvolvimento dos produtos. Os elementos, também chamados de elementos de design, conforme Treptow (2013, p. 126), permitem com o que a pensamento projetual assuma materialidade e, dessa forma, se aproxime das características necessárias para a criação em design de moda. 
A cor, neste contexto, integra os elementos e algumas referências podem ser retiradas a partir de uma depuração do moodboard, uma vez que, por seu atributo visual, ele permite a aplicação de tonalidades cromáticas que componham o perfil da marca e das tendências. A determinação de um tema seguirá, naturalmente, uma diretriz associada às etapas anteriores da metodologia.

É comum, nos processos de criação de painéis e de busca pelas cores, que sejam aplicados recursos digitais, como o uso de softwares gráficos. No entanto, um alerta a ser feito para tal situação é a utilização da ferramenta conta-gotas que identifica a cor de uma unidade muito pequena da imagem, um pixel no caso de imagens bitmaps. Apesar de sugerir precisão, o uso da ferramenta limita a seleção das cores, fazendo com que o conjunto de tonalidades pinçadas não correspondam a um olhar mais geral sobre a referência criativa do painel. Frente a isso, é necessário ter clareza de que o painel representa um tema e ele deve ser considerado em sua totalidade. A sua apreciação favorece a sensibilidade do olhar e o direcionamento da criação, solicitando que o designer exerça uma postura ativa perante à materialidade dos objetos que projeta. 
Figura 4. Exemplo de moodboard com apresentação de referências cromáticas oriundas das características das imagens.

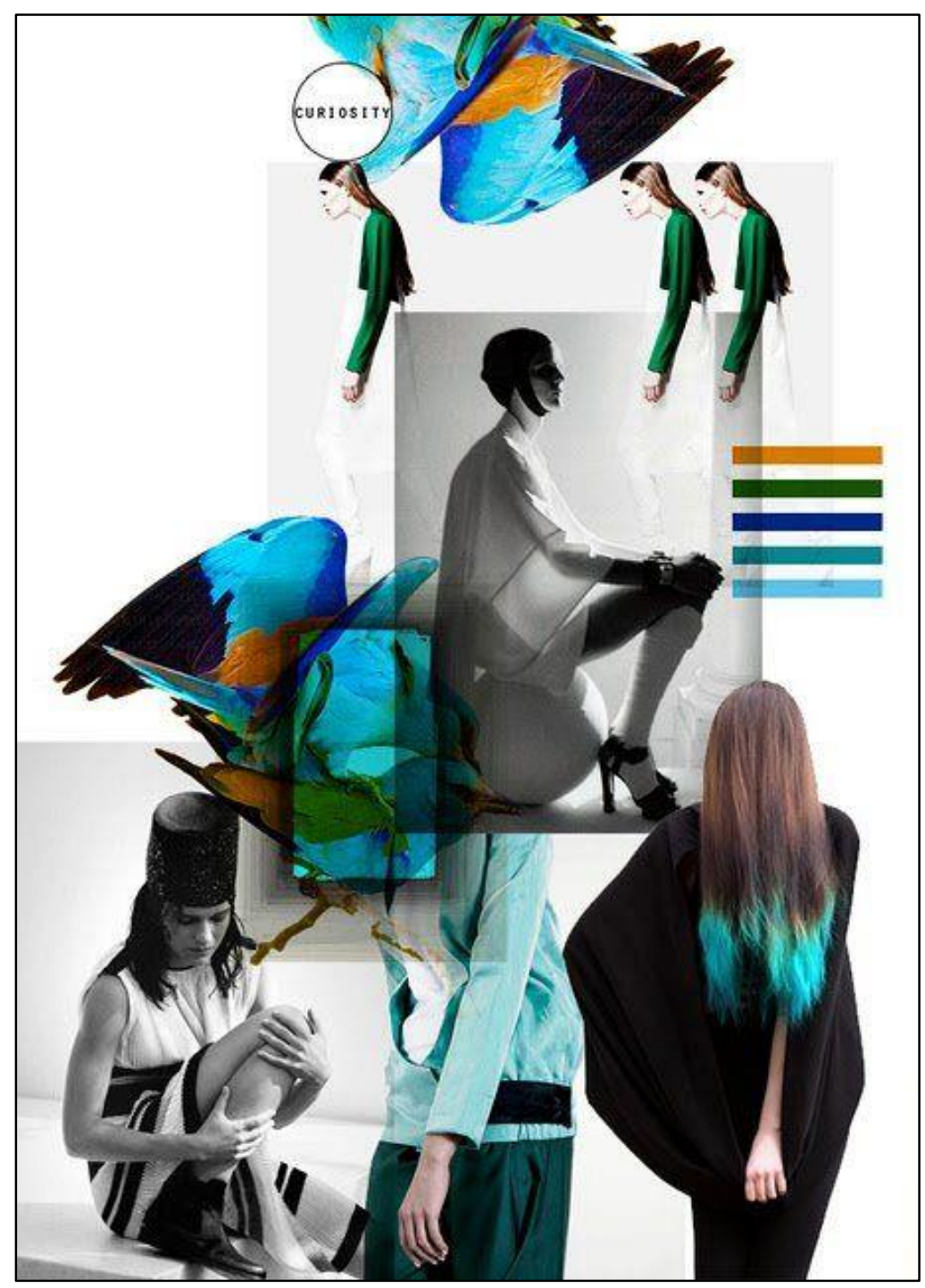

Fonte: Pinterest (2019).

As cores encontradas no moodboard não necessariamente se tornarão aquelas a formarem a cartela de cores, porque o processo de criação da cartela requer um rigor de ordem técnica e representa a confirmação das referências de cores da coleção. O tema e o painel estabelecem uma etapa da metodologia que prevê a determinação de critérios criativos que são inerentes ao processo projetual do design. A ação de percorrer a etapa do tema e transformá-lo em painel faz 
emergir outras referências de cores que correspondem a apostas da marca diante de seu perfil e das tendências encontradas no mercado. As referências desta etapa se juntam àquelas anteriores e, para que a passagem de todas estas cores aconteça na cartela de cores, o funil de decisões deve ser totalmente atravessado, para que sejam colocados em pauta os critérios estabelecidos.

\section{Cartela de cor}

Tendo em vista as três etapas: marca, tendências e temamoodboard, a primeira consideração a ser feita é que a cartela de cores corresponde a convergência das etapas anteriores, pois é o resultado do funil de decisões. Pela convergência que alude, ela exige que todos os critérios tenham sido atendidos e fundidos em uma resposta coerente a eles.

Um caminho que se pode ser definido é que os critérios de cores e harmonias observados no perfil da marca sejam mantidos e destacados na pesquisa das tendências. A partir disso, as cores encontradas nas tendências devem ser levadas para uma conferência com aquelas do tema e do moodboard. A equiparação das cores do painel com as indicadas pelas tendências formula uma síntese que resulta na cartela de cores, transparecendo a sequência de critérios desde a marca até os índices de criação.

Algumas referências bibliográficas, como Treptow (2013, p. 109), mencionam que o número de cores da cartela pode variar entre seis e doze. Embora esta orientação seja indicada para que a cartela não se torne extensa e não promova um alinhamento das referências, é importante salientar que não há regras sobre número de cores da cartela. De um modo geral, podemos dizer que ela vai depender da extensão da coleção e do número de produtos, conforme apontam as 
considerações sobre o dimensionamento de coleção de produtos de moda (TREPTOW, 2013; FRINGS, 2012; SAYEG; DIX, 2015).

Um dos pontos importantes a se considerar é que sejam definidas as cores lisas dentro da cartela de cores. Dependendo das técnicas de estamparia empregadas para o desenvolvimento dos produtos, algumas cores podem ser obtidas pelo resultado de estampas, sem impactar o investimento na compra de tecidos lisos. Quanto maior a diversidade de cores de um mesmo produto, mais profunda se torna a coleção, o que gera um sinal para o critério estratégico de dimensionamento do projeto. Projetar uma coleção na qual todas as cores da cartela representem tecidos lisos para a criação dos produtos é um ato de coragem frente aos direcionamentos produtivos, já que os riscos de variação se elevam e há chance de prejuízos na unidade estética da coleção, bem como no âmbito do consumo.

A consideração acima se associa ao que Treptow (2013, p. 110) afirma sobre cores principais e cores complementares na formação da cartela de cortes. Ela diz que as primeiras se referem àquelas mais utilizadas e as segundas são aquelas que aparecem em menor quantidade. A distinção desta característica favorece um pensamento projetual mais alinhado e atento à configuração a que os produtos são atribuídos.

Frings (2012, p. 217) comenta que uma diretriz para o desenvolvimento dos produtos é a formação de grupos que possibilitem a criação de diversidade dentro da coleção. Nesse sentido, a cor deve ser tomada como elemento que auxilia o agrupamento de produtos, criando uma unidade estética entre eles. Os grupos, chamados de famílias (SAYEG; DIX, 2015, p. 100), se identificam porque são gerados por harmonias específicas, oriundas de diferentes combinações de 
cores presentes na cartela. Com isso, a seleção de cores para a criação da cartela deve favorecer a geração de harmonias para que seja possível a formação de famílias. Quanto mais as tonalidades apresentarem variação de luminosidade e saturação, maiores serão as possiblidades de contrastes, o que pode ser tomado com um índice para a distinção dos agrupamentos de produtos.

Por fim, um tópico específico que pode ser associado às cartelas de cores é o visual merchandising. A partir do funil de decisões que a metodologia prevê, a cartela de cores pode ser utilizada em consonância às práticas de apresentação dos produtos para a venda. Nesse sentido, a formação das famílias por meio de harmonias poderia ser seguida de uma separação das cores da cartela por períodos que correspondem às diferentes entradas de produtos nas lojas. $A$ periodização pode ser estabelecida por critérios como estações, datas comemorativas, eventos, etc. O importante a destacar é que a periodização das cores nas cartelas produz um efeito de dosagem dos produtos para a venda, o que gera no público consumidor a impressão constante de novidade, como já é observado nas estratégias produtivas oriundas do fast fashion (CIETTA, 2010).

Podemos dizer que tudo isto afeta a disposição usual das cartelas de cores, pois elas tendem a se transformar para contemplar as diferentes estratégias que podem ser associadas às suas funções. Empregar cartelas nas quais as referências estejam lado a lado e sejam somente resultado da intuição dos designers demonstra uma limitação do pensamento projetual, já que sua forma não evidencia a importância que ela pode ganhar no desenvolvimento de produtos. Neste artigo, a intenção foi demonstrar um primeiro passo nos estudos das cartelas de cores pela ótica da prática do design de moda. Com isso, a investigação de novas formas 
de representação das cartelas a luz destas considerações se mostra promissora e é por este caminho que a pesquisa pretende seguir.

\section{Referências}

ALBERS, Josef. A interação da cor. São Paulo: Martins Fontes, 2009.

AMBROSE, Gavin; HARRIS, Paul. Design thinking. Porto Alegre: Bookman, 2011.

BARROS, Lilian Ried Miller. A cor no processo criativo: um estudo sobre a Bauhaus e a teoria de Goethe. 2. ed São Paulo: Ed. Senac, 2007.

BAXTER, Mike. Projeto de produto: guia prático para o design de novos produtos. 3. ed. 2. reimp. São Paulo: Edgard Blücher, 2011.

CIETTA, Enrico. A revolução do fast-fashion: estratégias e modelos organizativos para competir nas indústrias híbridas. São Paulo: Estação das Letras e Cores, 2010.

EVANS, Caroline. O espetáculo Encantado. Fashion Theory, v. 1, n. 2, p. 31-70, jun. 2002.

FÁBULA. 2018. Disponível em: https://www.afabula.com.br/. Acesso em: 17 nov. 2018.

FORTY, Adrian. Objetos de desejo: design e sociedade desde 1750. São Paulo: Cosac Naify, 2007.

FRASER, Tom; BANKS, Adam. 0 essencial da cor no design. São Paulo: Ed. Senac, 2011.

FRINGS, Gini Stephens. Moda: do conceito ao consumidor. 9. ed. Porto Alegre: Bookman, 2012.

GARCIA, Clarice. Color forecasting: as previsões de tendências de cores na moda. Brasília: SENAC, 2018.

ITTEN, Johannes. The art of color: the subjective experience and objective rationale of color. New York: John Wiley \& Sons, 2004.

KING, J. A.. Colour in fashion design. In.: Colour Design: Theories and Applications. Woodhead Publishing, 2017, p. 299-315. Disponível em: https://doi.org/10.1016/B978-0-08-1012703.00013-8. Acesso em: 25 maio 2019.

LIPOVETSKY, Gilles. O império do efêmero: a moda e seu destino nas sociedades modernas. $8^{a}$ reimp. São Paulo: Companhia das Letras, 2005.

MICHETTI, Miqueli. Moda brasileira e mundialização. São Paulo: Annablume, 2015.

PANTONE. 2019. Disponível em: https://www.pantone.com/colorintelligence/color-of-the-year/color-of-the-year-2019-paletteexploration. Acesso em: 25 maio 2019. 
PEDROSA, Israel. Da cor à cor inexistente. Rio de Janeiro: SENAC, 2009.

PEDROSA, Israel. 0 universo da cor. Rio de Janeiro: Ed. SENAC Nacional, 2003.

PINTEREST. 2019.2 Disponível em: https://br.pinterest.com/pin/634866878693900939. Acesso em: 25 maio 2019.

SANCHES, Maria Celeste de F. Moda e projeto: estratégias metodológicas em design. São Paulo: Estações das Letras e Cores, 2017.

SAYEG, Carla Marcondes; DIX, Luis Tadeu. Gerência de Produtos de Moda. Rio de Janeiro: SENAC, 2015.

STANSFIELD, Jill; WHITFIELD, T. W. Allan. Can future colour trends be predicted on the basis of past colour trends?: An empirical investigation. COLOR Research and application, v. 30, n. 3, p. 235-242, jun. 2005.2 Disponível em: https://doi.org/10.1002/col.20110. Acesso em: 25 maio 2019.

SVENDSEN, Lars. Moda: uma filosofia. Rio de Janeiro: Zahar, 2010. TREPTOW, Doris Elisa. Inventando moda: planejamento de coleção. 5. ed. São Paulo: Do autor, 2013. 